\title{
LA VILLA DE NOIA (A CORUÑA): RECORRIDO POR SU ARQUITECTURA DE LA PRIMERA MITAD DEL SIGLO XX ${ }^{1 *}$
}

\section{THE TOWN OF NOIA (A CORUÑA) TRAVEL AROUND ITS ARCHITECTURE DURING THE FIRST HALF OF THE 20th CENTURY}

\author{
MÓNICA VÁZQUEZ ASTORGA** \\ Universidad de Zaragoza
}

\begin{abstract}
Sumario
Este texto está dedicado a la arquitectura proyectada y construida en Noia (A Coruña) en la primera mitad del siglo XX. El crecimiento industrial y económico de este núcleo urbano favoreció la temperada introducción de los estilos arquitectónicos en alza en ese momento, que vino de la mano de prestigiosos arquitectos de la época, asentados en las capitales de provincia gallegas. Esta arquitectura se concreta fundamentalmente en edificios de viviendas y en establecimientos de ocio y espectáculo, en los que fue posible el triunfo de los nuevos lenguajes arquitectónicos.
\end{abstract}

\section{Palabras clave}

Arquitectura gallega contemporánea, arquitectura noiesa contemporánea, edificios de viviendas y establecimientos de ocio y espectáculo, crecimiento industrial y económico.

\begin{abstract}
This text is a result of a lengthy investigation that explores the architecture that designed and constructed in Noia (A Coruña) during first half of the 20th century. The industrial and economic growth of this urban nucleo, favored the temporary introduction of the rising architectonic styles, designed by the hand of prestigious architects of the time, rooted in in the Galician provincial capitals. This architecture essentially is notable in the construction of houses and establishments of leisure and spectacle, in which the triumph of the new architectonic languages was possible.
\end{abstract}

\section{Key Words}

Contemporary Galician architecture, contemporary Noian architecture, houses and establishments of leisure and spectacle, industrial and economic growth.

$1 *$ Recibido/Received 25.05.2009. Aceptado/Accepted 10.10.2009 


\section{PRÓLOGO}

En estas páginas se analiza la arquitectura proyectada y construida durante la primera mitad del siglo XX en Noia (A Coruña), a partir de la documentación consultada en el Archivo Municipal de esta localidad. Se trata de una aproximación a este tema, con la que se pretende contribuir al conocimiento del patrimonio arquitectónico de la villa de Noia y abrir el camino a posibles futuras investigaciones.

Esta arquitectura de la primera mitad del siglo XX, que se define esencialmente en edificios residenciales y de ocio y espectáculo (promovidos por una clientela privada), es reflejo de la prosperidad industrial y socio-económica vivida por Noia en esa época.

Antes de pasar a su estudio, se traza un breve recorrido por el panorama arquitectónico de la primera mitad del siglo XX en Galicia, con el objetivo de determinar el contexto en el que ésta debe ser considerada.

\section{LA ARQUITECTURA DE LA PRIMERA MITAD DEL SIGLO XX EN GALICIA.}

La lenta evolución estilística que ha caracterizado a la historia de la arquitectura, sufrió, en las primeras décadas del siglo XX, una aceleración con constantes cambios formales ${ }^{2}$.

Después de un período de dominio de las formas tradicionales de los estilos históricos o de los estilos regionales, comienzan a tomar cuerpo, hacia mediados de la década de los veinte, nuevas ideas, y aparecen los primeros ejemplos de una arquitectura que expresa una sensibilidad tendente a la modernidad. Al mismo tiempo que esa sensación de cambio se constata el sentimiento de decadencia; de ahí que el panorama arquitectónico de estos años esté presidido por el conflicto entre tradición y modernidad. En el caso de Galicia, la arquitectura en la década de los treinta, como indica Fernando Agrasar, se incorpora a la modernidad añadiendo a sus

\footnotetext{
**Profesora del Departamento de Historia del Arte de la Universidad de Zaragoza. Investiga acerca del arte y cultura contemporáneos. Correo electrónico: mvazquez@unizar.es

Este artículo se ha realizado con una ayuda del Programa Europa XXI de Estancias de Investigación (2008), patrocinado por la Diputación General de Aragón y por la Caja de Ahorros de la Inmaculada. Número de referencia de la ayuda concedida: $\mathrm{CH} 13 / 08$.

2 SORALUCE BLOND, José Ramón, "Introducción", AA. VV., Artistas galegos. Arquitectos. Arquitectura modernista, ecléctica e rexionalista, Vigo 2002, 15.
} 
propios códigos los nuevos mensajes visuales de las vanguardias ${ }^{3}$. La asimilación del ideario moderno fue más bien formal y visual, sin la aproximación convencida a la base ideológica del Movimiento Moderno.

En este contexto desarrollaron su actividad constructiva en Galicia un grupo de arquitectos que significaron lo más notable de su profesión. Se formaron en la última década del siglo XIX o en las dos primeras del siglo siguiente, en un ambiente dominado por el eclecticismo y por el regionalismo (inspirado en el románico, en el barroco compostelano y en la arquitectura de pazo como expresión del pasado más distintivo de Galicia). Esta formación no será óbice para que se vinculen al modernismo o se decanten, con un grado mayor o menor de compromiso, hacia el racionalismo, caso de Pedro Mariño Ortega (1865-1931), Julio Galán y González Carvajal (18751939), Rodolfo Ucha Piñeiro (1882-1981), Leoncio Bescansa Casares (1879-1957), Eduardo Rodríguez Losada Rebellón (1886-1973), Rafael González Villar (18871941), Peregrín Estellés (1891-1981) o Antonio Tenreiro (1893-1969). Sin embargo, las innovadoras propuestas llegaron a Galicia a través de un grupo de arquitectos nacidos en la primera década del siglo XX, que comenzaron sus carreras en los años veinte y fueron llegando a las ciudades gallegas desde los dos únicos centros de formación en aquel momento: Madrid y Barcelona, desde los que se difunde la nueva arquitectura $^{4}$. En este sentido, cabe destacar a Santiago Rey Pedreira (1902-1978), Eloy Maquieira (1902-1944), José María Banet y Díaz Varela (1903-1984), Antonio Álex Reinlein (1905-1980), José Caridad Mateo (1906-1996) y Francisco Castro Represas (1905-1997) ${ }^{5}$ quienes, en realidad, dispusieron de muy contadas oportunidades para poner en práctica sus modernos planteamientos y que, tras la contienda civil, tendieron a anular cualquier trazo moderno, portador de connotaciones ideológicas. La actividad de estos arquitectos intenta "disfrazar" sus obras para poder seguir introduciendo pequeños pero importantes cambios en la arquitectura: plantas funcionales, utilización sistemática de recursos, nuevas tecnologías constructivas, dejando una apariencia, vestigios de decoración que engañaran a los revisores del régimen ${ }^{6}$.

En relación con esto, cabe decir que así como en Galicia se constata un retraso en la asimilación de nuevos planteamientos en el campo de la arquitectura, debido,

\footnotetext{
${ }^{3}$ GARCÍA BRAÑA, Celestino y AGRASAR QUIROGA, Fernando (eds.), Arquitectura moderna en Asturias, Galicia y León, ortodoxia, márgenes y transgresiones, 1998, 111.

4 AGRASAR QUIROGA, Fernando, Vanguardia y tradición. La arquitectura de la primera modernidad en Galicia, A Coruña 2003, 47.

${ }^{5}$ Estos profesionales continuaron el camino abierto hacia esas corrientes innovadoras por arquitectos como González Villar.

6 MONTANER, Joseph María y MUXÍ, Zaida, "Introducción”, AA. VV., Artistas galegos. Arquitectos. Do racionalismo modernismo á 'a modernidade, Vigo 2002, 16.
} 
en gran medida, a su condición periférica respecto a los centros de discusión de la arquitectura moderna y a la pertenencia a una cultura con fuertes tradiciones constructivas, tipológicas y de relación con el medio, también llama la atención el hecho de que la vinculación al discurso moderno se mantiene hasta prácticamente finales de la década de los cuarenta (construyéndose, en estos años, algunas piezas interesantes del heterodoxo racionalismo gallego), no triunfando las formulaciones de inspiración "imperialista" hasta los años cincuenta.

Tras la contienda civil, el lenguaje funcional de la nueva vanguardia europea sufre, como en el resto del panorama nacional, un estancamiento. En los años cuarenta se produce una vuelta a una inspiración en los estilos históricos, principalmente en el barroco, buscando revivir caducas glorias imperiales en el campo político. Habrá que esperar, en el filo de los sesenta, para que se retome el interrumpido discurso arquitectónico moderno.

\section{LA ARQUITECTURA NOIESA DE LA PRIMERA MITAD DEL SIGLO XX}

La villa de Noia se localiza en la provincia de A Coruña, al fondo de la ría de Muros y Noia, y fundamenta su organización económico-social en actividades industriales, mercantiles y artesanales. Es una de las poblaciones más destacadas de Galicia por su ilustre pasado así como por su belleza urbana y monumental. Aparece vinculada en el curso de su historia a Santiago de Compostela, quedando sometida entre los siglos XII y XIX a la Mitra Compostelana. Su identidad medieval se reconoce en su entramado urbanístico, en el que la piedra y el soportal se convierten en sus elementos definidores. De hecho, su casco histórico fue declarado Conjunto Histórico-Artístico en el año $1985^{7}$. Afirma la tradición que es tierra de artistas, y de un gran desarrollo artístico (esencialmente durante la época medieval y la moderna), que han hecho de ella una pequeña Florencia atlántica ${ }^{8}$.

Como se ha indicado anteriormente, este trabajo pretende ser una aproximación al estudio de la arquitectura proyectada y construida en Noia durante la primera mitad del siglo XX. Para ello, se cuenta con una fuente excepcional como son los expedientes de obras conservados en el Archivo Municipal ${ }^{9}$, que corresponden a

7 SORALUCE BLOND, José Ramón y FERNÁNDEZ FERNÁNDEZ, Xosé (directores), Arquitecturas da provincia da Coruña, Comarca de Muros e Noia III, A Coruña 1998, 228.

${ }^{8}$ MARIÑO, Xoán Xosé, "A Arte”, AGRELO, Xosé y GARCÍA, Pedro (coords.), Noia. Ribeiras de mar enxoito, A Coruña 2003, 174.

9 En este punto, quiero expresar mi agradecimiento al Excmo. Concello de Noia y, de manera especial, a José Manuel Rodríguez Anido por haberme facilitado la consulta del Archivo Municipal de Noia. 
obra civil y, preferentemente, a edificios residenciales y de ocio y espectáculo. Sin embargo, los primeros proyectos localizados datan de comienzos de la década de los treinta, existiendo, por tanto, una considerable laguna documental a la hora de analizar la actividad arquitectónica desarrollada con anterioridad a estos años. Asimismo, los expedientes de obras relativos a edificios singulares del patrimonio arquitectónico noiés ${ }^{10}$, como es el caso del Teatro Coliseo Noela y del Casino, se encuentran extraviados.

En este contexto, cabe mencionar que el Teatro Coliseo Noela fue promovido por Manuel Domínguez Lestón, Primitivo Trigo Pardiñas y Ramón Mariño Neu en 1919 como edificio para teatro y espectáculos musicales, inaugurándose el 24 de abril de 1921 (figura 1). A principios del siglo XX existían diversos locales en Noia para llevar a cabo representaciones teatrales (como el habilitado en el convento de San Francisco), pero se decide emprender la construcción de un edificio de nueva planta que resultase, como indica la documentación consultada, "adecuado y acorde al rango de la villa"11. Como lugar de emplazamiento se elige la rúa do Curro, que constituye uno de los principales ejes urbanos. Tiene dos plantas: en la baja, se abren cinco arcadas y, en la planta noble, cinco vanos, destacando el cuerpo central en anchura y altura, que presenta un remate a modo de ático. Su fachada principal aúna dos lenguajes arquitectónicos: uno, deudor del modernismo, evidente en la resolución y ornamentación de los vanos, y, otro, de la tradición constructiva local, en los soportales de la planta baja. En los años setenta fue convertido en cine y el 24 de enero de 1990 fue declarado inmueble de interés público, social y cultural. En la década de los noventa se redacta y acomete un proyecto de restauración con el fin de rehabilitar este edificio, que se encontraba en estado de abandono y deterioro, produciéndose la recepción de las obras en julio de 2002. De este modo, la villa de Noia recupera para los noieses uno de los edificios más significativos de su pasado.

Por su parte, el Casino (rúa de Galicia, 10) fue construido bajo la dirección del maestro cantero Pepe da Agulla a finales de la década de los veinte del siglo pasado como centro socio-cultural. Es un edificio entre medianeras, con planta baja y dos alzadas, rematadas con un cuerpo central destacado en altura. Su fachada principal despliega en sillería un repertorio formal ecléctico. En planta baja presenta un vano central con dos columnas que se transforman en pilares en los cuerpos superiores. Asimismo, en planta baja, a los lados, se sitúan las entradas al inmueble en

10 En este contexto, cabe citar indudablemente la Central Eléctrica del Tambre, obra del arquitecto porriñés Antonio Palacios Ramilo. Sobre este edificio cf. GARCÍA VIDAL, Pedro, "O arquitecto Antonio Palacios no Concello de Noia", Alameda, 12 (xuño 2003), 24-30.

11 Archivo Municipal de Noia, Caja "Teatro Coliseo Noela". 
arco de medio punto. A mencionar es el balcón de la primera planta con barandilla de hierro forjado y los dos laterales con balaustres labrados en cantería, mientras que en el piso superior el balcón central es de cantería y los de los laterales de hierro. Este edificio se halla, en la actualidad, en estado de abandono, esperando una anhelada intervención que le salve del más absoluto olvido.

Como se ha señalado anteriormente, los primeros expedientes de obras localizados están fechados a principios de la década de los treinta y hacen referencia, esencialmente, a la edificación de viviendas o a su reforma (principalmente, de la fachada), con el fin de dotarlas de un aspecto acorde con los gustos de la época.

La morfología urbana de Noia sufre las primeras alteraciones a finales del siglo XIX y principios del XX, que conllevan, entre otras consecuencias, una agresión contra el recinto amurallado que protegía el centro histórico y limitaba su expansión urbana. Con el derribo de las murallas y la integración de los espacios extramuros en el conjunto del recinto histórico la villa pierde, en gran parte, su identidad medieval. Asimismo, a finales del siglo XIX se emprende el proceso de construcción de los malecones, que va paralelo a la venta de terrenos, en los que se emplazan nuevas edificaciones ${ }^{12}$. A comienzos de la década de los cuarenta se produce un auge demográfico que favorece la expansión urbana. En este contexto debe entenderse el impulso dado a la actividad constructiva noiesa en este momento. Las viviendas de nueva planta acometidas durante los años treinta y cuarenta se emplazan en amplias (y, en algunos casos, recién creadas) vías: Malecón de Gasset, Malecón de Cadarso, Carreiriña do Escultor Ferreiro, rúa Porta da Villa y rúa de Galicia, que bordean el núcleo histórico. Sin embargo, las casas que fueron reformadas en estos años se ubican, preferentemente, en el casco antiguo de Noia. Este hecho evidencia el importante cambio producido en el espacio residencial.

La documentación consultada pone de manifiesto que la actividad constructiva se encontraba, en la década de los treinta, en manos de dos maestros de obras: José Filgueíra y Antonio Mato ${ }^{13}$.

El maestro de obras José Filgueíra es el autor de la mayoría de las construcciones y obras de reforma emprendidas en la década de los treinta en Noia. A él se debe un proyecto de pabellón para la Sociedad Liceo de Noia, para el que se solicita la pertinente licencia en marzo de 1933 (figura 2) ${ }^{14}$. En relación con esto, cabe

12 GARCÍA VIDAL, Pedro, "Sobre a paisaxe construída do casco histórico noiés", Alameda, 5 (setembro 2001), 25-27.

13 A este respecto, cabe decir que el gremio de los canteros fue uno de los más numerosos en la villa de Noia, dado que durante muchos años las construcciones fueron exclusivamente de piedra.

14 Archivo Municipal de Noia, Caja 266 (1931-1937). 
mencionar que durante la dictadura primorriverista se crean en la villa de Noia, por iniciativa de la burguesía local, dos entidades relevantes en la vida socio-cultural noiesa: el Noia F.C. y la Sociedad Liceo. Según Xerardo Agrafoxo, esta Sociedad, fundada en 1928 como centro cultural y recreativo, se establece en el primer piso de la casa de rúa do Cantón, 43. Al poco tiempo, se traslada a rúa Porta da Vila, 10 (en la actualidad núm. 7), donde permanece hasta el 31 de diciembre de 1933. Ante el incremento del número de socios, el 1 de enero de 1934 cambia de sede, instalándose en rúa do Comercio, 11. Poco después, este local sufre un incendio que destruye sus instalaciones, teniendo que recurrir a estancias provisionales hasta que se desplaza nuevamente al edificio en rúa Porta da Vila, 7, donde permanece veintinueve años, emplazándose actualmente en las proximidades de la Alameda ${ }^{15}$. Por tanto, si el expediente localizado hace referencia a la solicitud de licencia por parte de Francisco Torres Fernández, presidente de la Sociedad Liceo, en marzo de 1933 para la construcción (en el llamado Campo de la Angustia) de un domicilio social para esta Sociedad conforme al plano de José Filgueíra, cabe suponer que se deseaba disponer de un inmueble de nueva planta en las inmediaciones del ocupado en aquellos momentos (rúa Porta da Vila, 7). Probablemente, al no materializarse este proyecto se opta por alquilar un local en rúa do Comercio, 11, en 1934. El edificio concebido por Filgueíra muestra una temperada deuda formal con el modernismo, asumiendo también elementos eclécticos. A este respecto, cabe decir que la presencia del modernismo en Noia es mínima, limitándose a este tipo de inmuebles de notable representatividad social.

A este maestro de obras corresponde también la construcción de varios edificios destinados a viviendas como el proyectado en 1938 en la avenida del General Franco (denominada actualmente rúa de Galicia) para Mariano Nimo Gómez ${ }^{16}$. Asimismo, se hizo cargo de obras de reforma como la efectuada en la casa propiedad de Ricardo Rama en rúa do Comercio, consistente en el aumento de un piso en altura ${ }^{17}$.

Junto a la actividad de José Filgueíra se advierte también la del maestro de obras Antonio Mato. Su labor se centra, principalmente, en obras de reforma, como las realizadas en 1938 en la planta baja (destinada a local comercial) del edificio propiedad de Santiago Peiteado Valls, situado en la calle de José Antonio Primo de Rivera (actual rúa do Cantón) ${ }^{18}$; o en 1939 en la casa de José Vázquez, emplazada

15 AGRAFOXO, Xerardo, 400 años na historia da vila de Noia. Dende a Idade Moderna ata a Segunda República, Noia 1991, 232-233.

16 Archivo Municipal de Noia, Caja 267 (1938-1940).

17 Archivo Municipal de Noia, Caja 266 (1931-1937).

18 Archivo Municipal de Noia, Caja 267 (1938-1940). 
en el número 1 de esta misma calle ${ }^{19}$. Asimismo, proyectó su propia casa (calle Luis Cadarso), en noviembre de 1940 (figura 3) ${ }^{20}$.

En estas viviendas, construidas o reformadas en los años treinta, se constatan una serie de elementos comunes. Fueron promovidas por una clientela privada, que demanda viviendas confortables en determinados sectores de la villa. Tienen, por lo general, planta baja y alta (y, excepcionalmente, planta baja y dos alzadas; destinándose la baja a uso comercial y las restantes a vivienda). Por tanto, son nuevas formas de edificación que se corresponden con un nuevo concepto de vivienda, en sustitución de la vivienda con soportal, de procedencia medieval. Los materiales empleados en la construcción son los habituales en la zona, recurriéndose a la mampostería en la cimentación y en las paredes laterales de elevación, a la sillería en la fachada principal, a la madera en la techumbre y carpintería y a la teja en la cubierta. Hacia finales de la década de los treinta, y seguramente para economizar gastos, comienza a emplearse el hormigón, que en fachada se reviste imitando sillería. Presentan, generalmente, una planta tradicional desde el punto de vista de la distribución interna (que recuerda a los esquemas de las viviendas decimonónicas). Sobre una planta alargada, se sitúa el núcleo de escaleras en un punto central, en torno a las cuales se disponen las distintas dependencias. En ocasiones, el arraigo a la tradición lleva al mantenimiento de la galería cubriendo la fachada posterior, como se advierte en el edificio que Antonio Mato proyecta como residencia familiar en noviembre de 1940 (figura 4).

A nivel de fachada, se caracterizan por la sencillez y sobriedad compositiva. Por lo general, presentan miradores en voladizo (cuyo espacio interior se corresponde con una de las piezas importantes de la vivienda: un salón o un dormitorio) o balcones con antepechos tubulares metálicos (pervivencia del vocabulario del ideario de la arquitectura moderna, cuya temperada irrupción en Noia fue fundamentalmente formal y visual). Es frecuente que se coronen por peinetas que amplían el horizonte modular de la fachada y que son deudoras de la estética déco. Este recurso compositivo es frecuente en inmuebles construidos en esta época en otras ciudades gallegas y, en concreto, en la producción de determinados arquitectos como Rafael Gónzalez Villar, cuyo Cine Avenida (proyectado en 1937, Cantón Grande, 18-20, A Coruña) se halla coronado por una peineta semi-octogonal. Por tanto, el mirador o el balcón volado sobre la planta baja se convierten en el elemento identificador de la arquitectura noiesa (y, en general, de la arquitectura coruñesa) de estos años. De hecho, son numerosos los proyectos de edificios destinados a vivien-

19 Archivo Municipal de Noia, Caja 267 (1938-1940).

20 Archivo Municipal de Noia, Caja 267 (1938-1940). 
das que, en la década de los cuarenta, lo incorporan, como es el caso de los citados a continuación: casa situada en rúa Porta da Vila, 9, que fue reformada y ampliada (dotándola de un segundo piso en altura) conforme a los planos redactados por José Filgueíra en septiembre de 1939 (figura 5) ${ }^{21}$; casa emplazada en avenida del General Franco (actual rúa de Galicia, 8), proyectada por el arquitecto Leoncio Bescansa en junio de 194322; casa ubicada en rúa Rodríguez Cadarso, 2, suscrita por Leoncio Bescansa en enero de 1946 23 ; o casa proyectada en Carreiriña do Escultor Ferreiro por Leoncio Bescansa en julio de $1947^{24}$.

Como puede comprobarse, hay que esperar al año 1943 para que la actividad constructiva en Noia se concentre en la figura de los arquitectos. Los maestros de obras antes citados siguen en activo, pero su presencia se concreta en núcleos poblacionales próximos a Noia. Así, el primer proyecto localizado firmado por un arquitecto fue realizado con motivo de la construcción de una casa en avenida del General Franco (actual rúa de Galicia, 8), para Secundino Tomé Carou, en el solar resultante de la demolición del edificio existente ocupado por la Administración de los Automóviles Castromil (figura 6). El arquitecto coruñés Leoncio Bescansa fue el encargado de redactar el proyecto en junio de 1943, en el que posteriormente se introducen una serie de modificaciones con la finalidad de dar a la fachada principal un aire más moderno y de dotar al edificio de otro piso en altura, constando, por tanto, de planta baja (destinada a comercio) y dos alzadas (para uso de viviendas en régimen de alquiler). En fachada presenta los característicos balcones de antepecho metálico unidos a miradores que vuelan sobre la planta baja. Este inmueble linda con el Casino y se encuentra hoy en día en estado de abandono. Esta tipología de edificio residencial va a ser utilizada por el arquitecto Bescansa en estos mismos años en lugares próximos a Noia y en otras ciudades coruñesas como Betanzos (figura 7) ${ }^{25}$, Riveira ${ }^{26}$ o Palmeira.

A partir de este momento, la actividad de Bescansa será importante en la villa, acometiendo la construcción de la mayoría de los edificios destinados a viviendas

21 Archivo Municipal de Noia, Caja 267 (1938-1940).

22 Archivo Municipal de Noia, Caja 268 (1941-1944).

23 Archivo Municipal de Noia, Caja 1.619 (1945-1948).

24 Archivo Municipal de Noia, Caja 1.619 (1945-1948).

25 Archivo Municipal de Betanzos, Caja 618.

${ }^{26}$ En esta misma línea, el arquitecto Leoncio Bescansa formula varias viviendas en Riveira como las proyectadas en calle Venecia (actual avenida General Franco), 121, en 1941 (Archivo Municipal de Riveira, Caja 44, expediente ${ }^{\circ}$ 32); en calle Romero y Rama (actual avenida Romero Ortiz), en 1943 (Archivo Municipal de Riveira, Caja 44, expediente n 151); y en calle Venecia, 154, en 1944 (Archivo Municipal de Riveira, Caja 45) (desaparecidas). 
promovidos en los años cuarenta. A este respecto, cabe citar la casa proyectada en rúa do Curro, 36, en agosto de 194327; y en rúa do Comercio, 3, en abril de 1944, con planta baja (para uso comercial) y dos alzadas (destinadas a vivienda) (figura $8)^{28}$. La línea de cornisa se corona con una balaustrada, recurso ya empleado por este arquitecto en otras obras suyas como en el antiguo Coliseo García Novoa (rúa San Agustín, 20) de Pontedeume, inaugurado en febrero de 1929. En este inmueble, Bescansa ensaya una estética ecléctico-academicista dominante en su producción de estos años.

Por tanto, la mayor parte de los edificios de nueva planta o reformados en la década de los cuarenta en Noia se debieron al arquitecto Leoncio Bescansa. Sin embargo, en el panorama de la arquitectura noiesa de estos años existen proyectos, en menor número, firmados por renombrados arquitectos de la época como Antonio de Cominges, José María Banet y Díaz Varela, Antonio Tenreiro, Peregrín Estellés y Antonio Vicéns Moltó.

El arquitecto vigués Antonio de Cominges, aunque trabajó principalmente en Vigo, dejó también obras en ciudades como Santiago de Compostela o Noia, deudoras de la tendencia regionalista del momento. Este profesional proyecta, en julio de 1944, una casa para Alejandro Barreiro en la confluencia de Carreiriña do Escultor Ferreiro con Malecón de Cadarso (figura 9) ${ }^{29}$. Consta de dos plantas y de un remate a modo de torre (en el chaflán), y tiene muros de ladrillo revestidos con sillería.

Por su parte, el arquitecto lucense Banet construye una casa en praza das Angustias, 3, conforme al proyecto suscrito en agosto de 1945 (figura 10) ${ }^{30}$. Tiene tres plantas en altura destinadas a vivienda y como sistema constructivo se recurre a cimientos y muros de hormigón en masa, pisos de forjados de hormigón armado sobre vigas y pilares del mismo material, pavimentos de madera y carpintería exterior e interior de madera de castaño. La fachada principal se halla revestida imitando sillería. Poco después, en mayo de 1951, este mismo arquitecto redacta el proyecto para una casa en avenida del General Franco (actual rúa de Galicia), con dos plantas: la baja, para ferretería y, la planta alta, para vivienda ${ }^{31}$. La actividad profesional de Banet se desarrolla principalmente en Santiago de Compostela, dado que fue nombrado arquitecto municipal en 1931. A él se debe la aproximación de la arquitectura santiaguesa al ideario de la modernidad. Los edificios de viviendas for-

27 Archivo Municipal de Noia, Caja 268 (1941-1944).

28 Archivo Municipal de Noia, Caja 268 (1941-1944).

29 Archivo Municipal de Noia, Caja 268 (1941-1944).

30 Archivo Municipal de Noia, Caja 1.619 (1945-1948).

31 Archivo Municipal de Noia, Caja 1.620 (1949-1952). 
mulados por Banet en Noia responden a los mismos planteamientos de los inmuebles santiagueses de estos años ${ }^{32}$. Estas edificaciones anuncian el viraje de su arquitectura hacia las exigencias del momento político que se vivía.

$\mathrm{Al}$ arquitecto coruñés Antonio Tenreiro se debe la proyección de un edificio de cinco plantas para sucursal del antiguo Banco de La Coruña en Noia (rúa de Galicia angular con rúa Porta da Vila), en noviembre de 1945 (figuras 11-12) ${ }^{33}$. La planta baja está destinada a oficina (en la actualidad, perteneciente a otra entidad bancaria) mientras que el resto de los pisos se reservan para viviendas. En este contexto, cabe recordar que este arquitecto redactó, en 1950, el edificio para sucursal del Banco de La Coruña (praza Otero Goyanes) de Riveira ${ }^{34}$. Ambos edificios responden a planteamientos similares, se emplazan en solares en esquina (estratégicamente situados a nivel urbanístico) y destacan por su monumentalidad. Además, se articulan, desde el punto de vista compositivo, en tres partes en altura (basamento, cuerpo principal y cuerpo superior), rematadas por un potente alero. Estos elementos se aprecian también en otras obras suyas como en el inmueble coruñés sito en rúa Concepción Arenal, 15, esquina con avenida General Sanjurjo. Asimismo, constituyen un claro testimonio de cómo la producción arquitectónica de Tenreiro (caracterizado por su talante progresista), opta, en los años de la posguerra, por la eliminación de cualquier trazo moderno (portador de connotaciones ideológicas) a favor de un historicismo ecléctico.

La aportación del arquitecto valenciano Peregrín Estellés (que compartió con Antonio Tenreiro estudio profesional en A Coruña) a la villa de Noia se limitó a una reforma efectuada en la casa de Andrés Hermida Blanco en rúa Porta da Villa, en junio de 194935; y la del arquitecto Vicéns Moltó a la proyección de un chalet para Benigno Martínez Balirach en Malecón de Gasset, en diciembre de 1951, en el que se advierte la asimilación de un lenguaje de marcado carácter regionalista ${ }^{36}$. Compuesto de sótano, planta baja y aprovechamiento en parte de la planta de cubierta, y destinado todo a una sola vivienda.

La década de los cincuenta sigue contando con la labor de la mayoría de los profesionales ahora citados, a la que se suman otros como los arquitectos Santiago Rey

32 En especial, cabe mencionar los edificios de viviendas santiagueses emplazados en el número 114-116 de la avenida de Rosalía de Castro, proyectado en 1942 (A.H.U.S., Fondo Municipal, A.M., 1.981 (1942), expediente $n^{\circ} 146$ ); y en el número 10 de rúa Montero Ríos, proyectado en 1945 (A.H.U.S., Fondo Municipal, A.M., 1.987 (1945), expediente nº 21).

33 Archivo Municipal de Noia, Caja 1.619 (1945-1948).

34 Archivo Municipal de Riveira, Caja 46.

35 Archivo Municipal de Noia, Caja 1.620 (1949-1952).

36 Archivo Municipal de Noia, Caja 1.620 (1949-1952). 
Pedreira y Juan González Cebrián. En estos años se constata una disminución de la actividad constructiva y la búsqueda de la inspiración en los estilos históricos, persiguiendo una pretendida identidad nacional.

\section{A LA MANERA DE EPÍLOGO}

La intensa actividad constructiva emprendida durante la primera mitad del siglo pasado (y, principalmente, en los años treinta y cuarenta, por una clientela privada) pone de manifiesto la importancia socio-económica de la villa de Noia.

El panorama arquitectónico analizado refleja que se barajan al mismo tiempo distintos lenguajes, como reflejo de la dialéctica entre tradición y modernidad que aporta los rasgos de identidad de la arquitectura gallega de este período. Asimismo, se ha dejado constancia de que Noia, además de poseer edificios singulares (religiosos, de carácter asistencial, casas nobles o pazos urbanos) convertidos en símbolo de la villa, también cuenta con edificios residenciales y de ocio de época contemporánea que forman parte fundamental de su patrimonio y de su memoria. 


\section{ANEXO DE IMÁGENES}

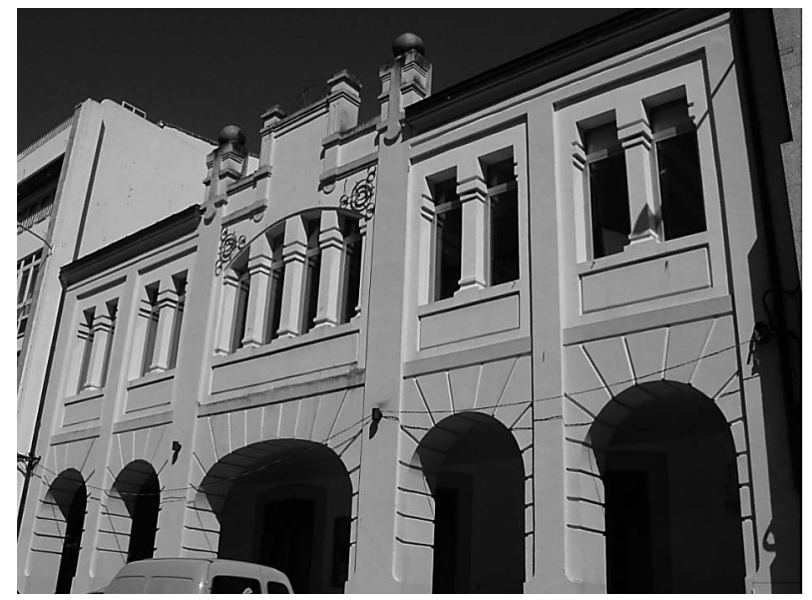

Figura 1. Fachada del Teatro Coliseo Noela, rúa do Curro, Noia.

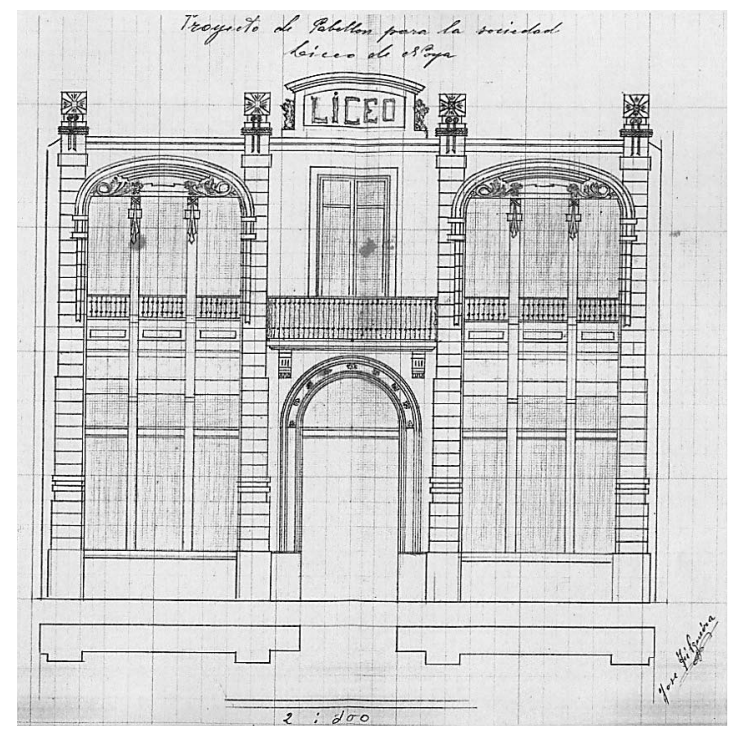

Figura 2. Proyecto de pabellón para la Sociedad Liceo de Noia, por el maestro de obras José Filgueíra 


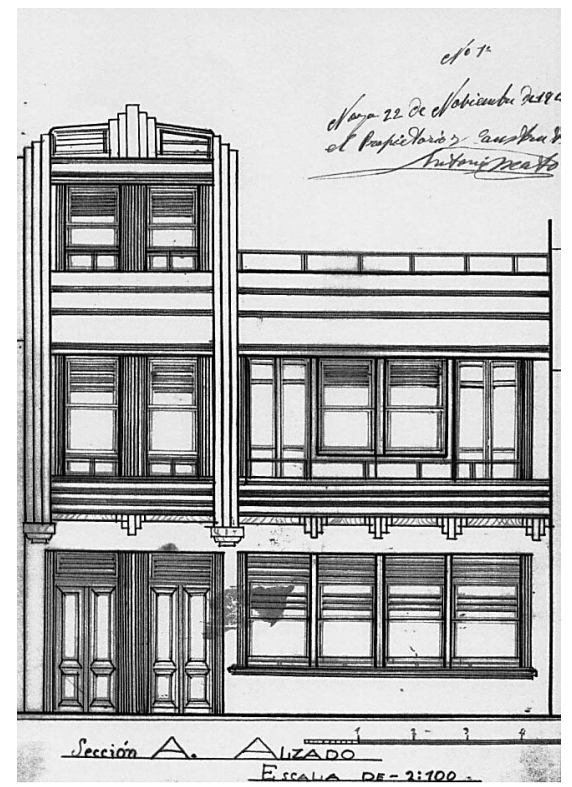

Figura 3. Fachada principal del edificio proyectado por el maestro de obras Antonio Mato en calle Luis Cadarso, Noia, noviembre de 1940.

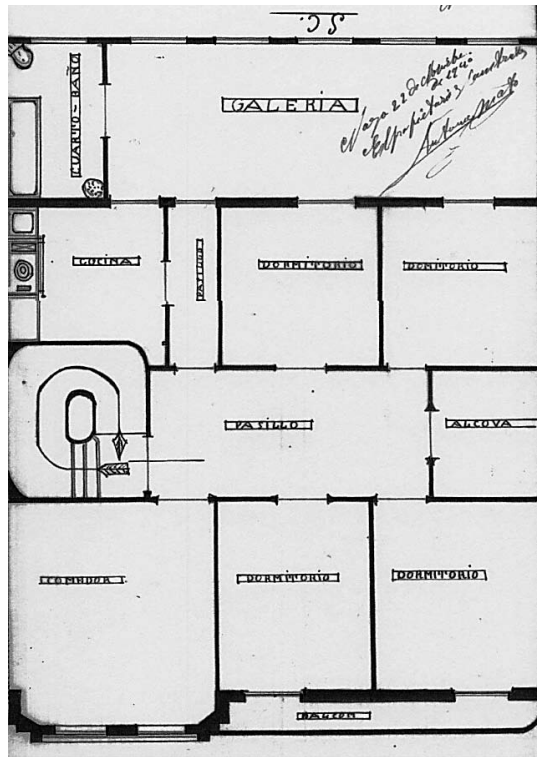

Figura 4. Planta del primer piso del edificio proyectado por el maestro de obras Antonio Mato en calle Luis Cadarso, Noia, noviembre de 1940. 


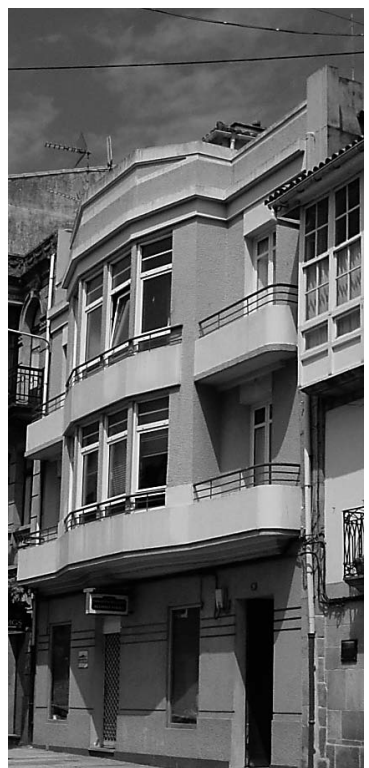

Figura 5. Fachada del Teatro Coliseo Noela, rúa do Curro, Noia.Figura 5. Edificio de viviendas en rúa Porta da Vila, 9, Noia.

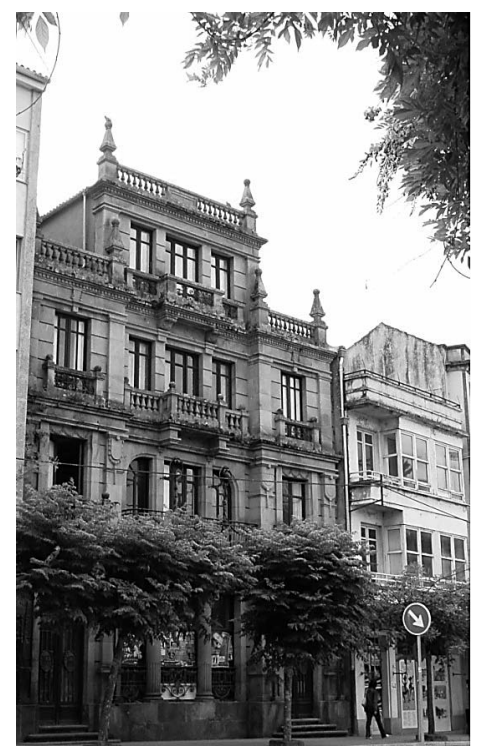

Figura 6. Fachada principal del edificio en rúa de Galicia, 8 (junto al Casino), Noia, proyectado por el arquitecto Leoncio Bescansa en 1943. 


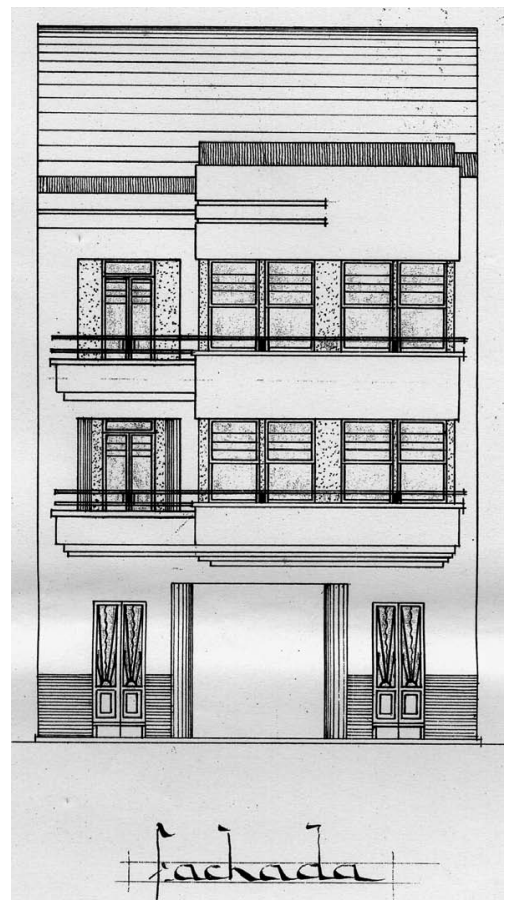

Figura 7. Reforma de fachada de edificio en rúa da Ribeira, 149, Betanzos, formulada por el arquitecto Leoncio Bescansa en 1941.

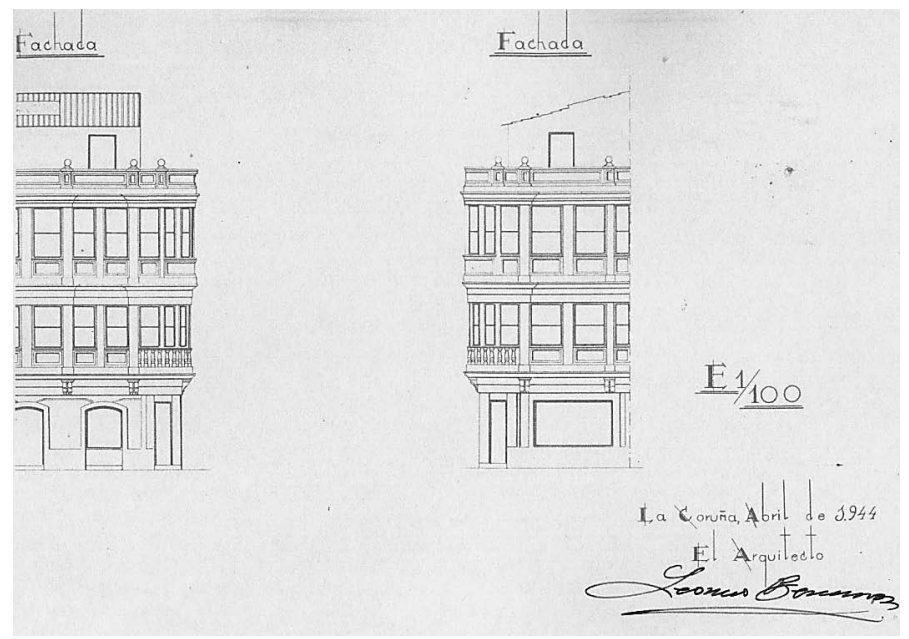

Figura 8. Fachada del edificio situado en rúa do Comercio, 3, Noia, por el arquitecto Leoncio Bescansa, 1944. 


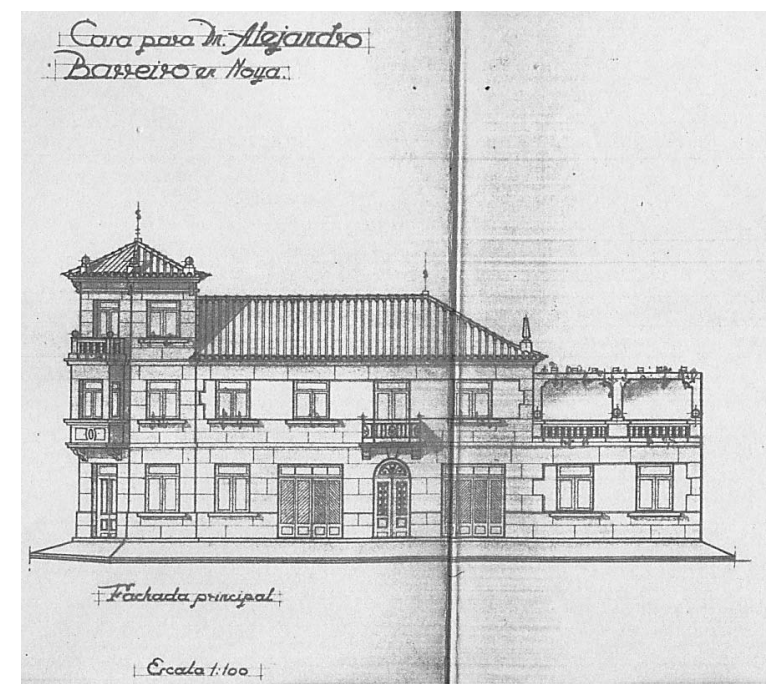

Figura 9. Casa en Carreiriña do Escultor Ferreiro angular con Malecón de Cadarso, Noia, proyectada por el arquitecto Antonio de Cominges en julio de 1944.

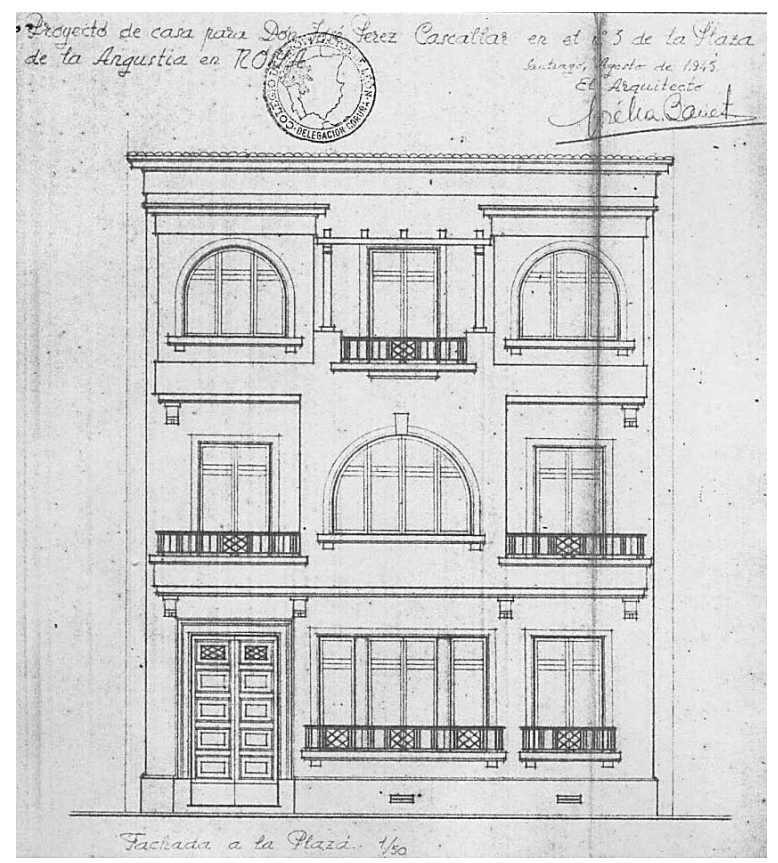

Figura 10. Fachada a la praza das Angustias, Noia, de la casa proyectada por el arquitecto José María Banet y Díaz Varela en agosto de 1945 


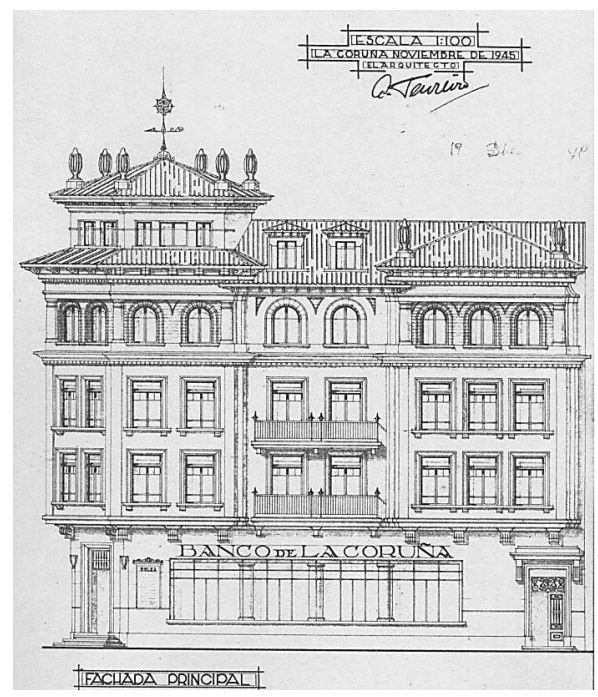

Figura 11. Fachada principal del edificio destinado a sucursal del Banco de La Coruña en rúa de Galicia angular con rúa Porta da Vila, Noia, por el arquitecto Antonio Tenreiro, noviembre de 1945.

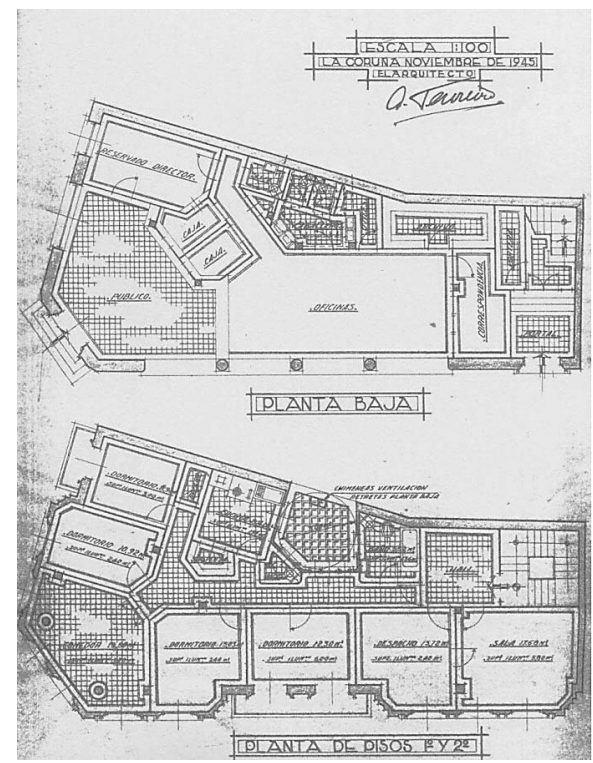

Figura 12. Planta baja y de pisos primero y segundo del edificio para sucursal del Banco de La Coruña, proyectado por el arquitecto Antonio Tenreiro en noviembre de 1945) 